\title{
Las prácticas pedagógicas mediadas por tecnologías digitales en espacios curriculares de alto contenido práctico ${ }^{1}$
}

\section{Teaching practices under digital technologies in curricular areas with high practical content}

\author{
Patricia Añón, Lucía Martínez y Verónica Perrone ${ }^{2}$
}

Fecha de recepción: 31 de marzo de 2020

Fecha de aceptación: 8 de octubre de 2020

\section{Resumen}

\begin{abstract}
Este artículo presenta una investigación sobre las prácticas pedagógicas mediadas por tecnologías digitales (TD) en espacios curriculares de alto contenido práctico (ECACP) de cursos correspondientes a algunas Áreas del Instituto Normal de Enseñanza Técnica (INET) en la modalidad semipresencial del Plan 2017. En esta modalidad está contemplado que los cursos con contenido práctico, como talleres y laboratorios, se impartan a través de una plataforma virtual del Consejo de Formación en Educación (CFE) y sean complementados con un treinta por ciento de actividades presenciales. Se cuenta, además, con la posibilidad de realizar videoconferencias. Compete a los docentes diseñar las estrategias que les permitan abordar los contenidos prácticos con la utilización de TD en la virtualidad; frente a esto surgen interrogantes referidas a los problemas con que se encuentran los docentes, cómo los enfrentan, cuáles son aspectos críticos para resolver, cuáles las prácticas exitosas que se pueden colectivizar y servir de insumos para otros docentes. Se realiza un abordaje
\end{abstract}

\footnotetext{
${ }^{1}$ Investigación realizada en el marco del curso «Iniciación a la investigación cualitativa y tecnologías digitales» del Consejo de Formación en Educación - Departamento de Tecnologías Digitales y Formación en Educación.

${ }^{2}$ Patricia Añón - Profesora de Informática egresada del Instituto Normal de Enseñanza Técnica. Maestranda en Enseñanza Universitaria de UdelaR. Profesora en el Consejo de Formación en Educación y en el Consejo de Educación Técnico Profesional de la ANEP. Correo electrónico: patricia.anon@cfe.edu.uy

Lucía Martínez - Licenciada en Diseño e Indumentaria egresada de la Universidad de la Empresa (UDE). Diplomada en Docencia Universitaria y de Nivel Superior (UDE). Profesora en el Consejo de Formación en Educación y en Educación Especial del Consejo de Educación Inicial y Primaria de la Anep. Correo electrónico: lucia.l.lu2@gmail.com

Verónica Perrone - Profesora de Ciencias Biológicas egresada del Instituto de Profesores Artigas. Maestranda en Enseñanza Universitaria de UdelaR. Profesora del Consejo de Formación en Educación de la ANEP. Correo electrónico: veronica.perrone@cfe.edu.uy
} 
Añón, Martínez y Perrone - Las prácticas pedagógicas mediadas por tecnologías digitales...

cualitativo del tema que podría enmarcarse en un estudio de caso en profundidad de carácter descriptivo en el que se han usado como instrumentos de recolección de datos, entrevistas semiestructuradas a tres docentes, la observación de sus aulas virtuales y el análisis de documentación.

Palabras clave: prácticas pedagógicas, tecnologías digitales, contenido práctico.

\section{Abstract}

This article summarizes a research about teaching practices under digital technologies (TD) in curricular areas with high practical content (ECACP) in blended-modality courses of Plan 2017, from the Instituto Normal de Enseñanza Técnica (INET). This type of classes, with practical content like workshops and lab work, are taught through a virtual platform from the Consejo de Formación en Educación (CFE) and are complemented with a thirty percent of in-person classes. There is also the possibility of using videoconferencing. Teachers are responsible for designing strategies to address the practical aspects of their courses using virtual digital technologies. Questions arise regarding the problems faced by the teachers, how they handle them, which are the critical aspects to solve and which are the most successful strategies that can be used as an input by other teachers. This is a descriptive study in which semi-structured interviews with three teachers, the observation of their virtual classrooms and the analysis of documentation have been used as data-collection instruments.

Key words: teaching practices, digital technologies, high practical content.

\section{Planteamiento del problema}

El propósito primario de esta investigación ha sido analizar las prácticas pedagógicas mediadas por tecnologías digitales (TD) en los espacios curriculares de alto contenido práctico (ECACP) que desarrollan los docentes de carreras semipresenciales del Instituto Normal de Enseñanza Técnica (INET) en el correr del año lectivo en 2018.

En INET, la experiencia de la oferta educativa en modalidad semipresencial es incipiente. A mediados del 2015, fue aprobada por el Centro de Formación en Educación (CFE) la primera experiencia de carreras docentes técnicas semipresenciales para las áreas Agraria y Eléctrica. En un principio se limitó la inscripción, pero en la actualidad está abierta a cualquier estudiante que cumpla con los requisitos establecidos por el CFE y se ha extendido a otras áreas disciplinares.

Uno de los principales retos de la formación de Maestros Técnicos tiene que ver con la implicancia de sus asignaturas con contenidos técnicos y/o prácticos, aspecto que se complejiza más si pensamos en su abordaje en carreras semipresenciales. Desde sus fundamentos, el plan vigente define estas asignaturas prácticas como: 
una modalidad de enseñanza y estudio caracterizada por la actividad y el tipo de desarrollo que prioriza, la investigación operativa, el trabajo en equipo y la producción colectiva que, en su aspecto externo, se distingue por la elaboración de un producto tangible. Los talleres están dirigidos especialmente al desarrollo de competencias para desempeñarse como profesional. (CFE, 2018, p.16)

Los docentes de las carreras de INET que iniciaron su experiencia en la modalidad semipresencial tuvieron previamente, en su mayoría, trayectoria profesional en la presencial. A partir del 2015, cuando se implementó esta nueva modalidad, comenzaron a desarrollar sus prácticas de enseñanza valiéndose de la mediación de las TD que ofrece la plataforma institucional (en ese momento CREA 2 de Ceibal ${ }^{3}$, basada en el software de Schoology) y de otros recursos disponibles. En el caso particular de los Maestros Técnicos y de asignaturas con énfasis en el contenido práctico, se presentan interrogantes referidas a los problemas con los que se encuentran los docentes, cómo los enfrentan, cuáles son aquellos aspectos críticos que no han logrado resolver y cuáles estrategias han resultado exitosas en el desarrollo de contenidos prácticos que se puedan colectivizar y servir de insumos para otros docentes.

\section{Objetivos de la investigación}

\section{Objetivo general}

Analizar las prácticas pedagógicas mediadas por TD que desarrollan profesores de las carreras docentes semipresenciales de INET en espacios curriculares con alto contenido práctico, de taller o laboratorio.

\section{Objetivos específicos}

- Identificar las prácticas pedagógicas mediadas por TD que desarrollan los docentes seleccionados en modalidad semipresencial para los ECACP.

- Caracterizar las prácticas pedagógicas mediadas por TD en la modalidad semipresencial para los ECACP.

- Sistematizar las estrategias y actividades desarrolladas en las prácticas analizadas.

\section{Consideraciones teóricas previas}

Como punto de partida y con el fin de considerar los aspectos a ser observados en las prácticas pedagógicas investigadas, se tomó como referencia el planteo de Huberman, que las considera como un proceso "consciente y deliberado» cuyo objetivo último es «mejorar desempeños y resultados, estimular el desarrollo para la renovación en campos académicos, profesionales o laborales y formar el espíritu de

\footnotetext{
${ }^{3}$ Ceibal, retroacrónimo que significa Conectividad Educativa de Informática Básica para el Aprendizaje en Línea, programa creado en 2007 en Uruguay.
} 
Añón, Martínez y Perrone - Las prácticas pedagógicas mediadas por tecnologías digitales...

compromiso de cada persona con la sociedad y particularmente para con la comunidad en la cual se desenvuelve» (1999, p.25). Más allá de este enfoque sobre el concepto de práctica pedagógica, tanto Pozo (2014) como Alliaud $(2010,2017)$ confirman la tendencia de los profesores en los niveles terciarios a replicar la forma en que ellos aprendieron en su propio estilo de enseñar. Una de las salidas propuesta a esta encrucijada (Alliaud, 2005; Montero, 2016) se da a través de la reflexión continua sobre la experiencia vivida y sobre las prácticas, para evitar el riesgo de repetir lo que no se quiere.

En su artículo del 2005, Koehler y Mishra desarrollan la noción de los tipos de saberes que un docente debería manejar en sus prácticas incorporando la dimensión del conocimiento tecnológico (TK por technological knowledge) y cómo, de su intersección con las dimensiones del contenido y pedagógicas antes descritas por Schulman (1986) — СK (content knowledge) y PK (pedagogical knowledge)—, surge el modelo TPACK (technological pedagogical content knowledge). En 2013, Koehler, Mishra y Cain, revisan estos conceptos y aclaran que, al referirse al conocimiento tecnológico, no se limitan a lo digital ni a las «nuevas tecnologías» y reconocen las dificultades a las que se enfrentan los docentes al trabajar en contextos dinámicos y de alta complejidad. Las decisiones que toman los docentes en su uso y en su no uso implica conocer sus facilidades y restricciones; también se debe considerar los factores sociales y contextuales que complejizan la relación entre la enseñanza y la tecnología, puesto que esta está lejos está de ser neutral.

Figura 1

El marco TPACK y sus saberes que lo componen, tomado de (Koehler, Mishra \& Cain, 2015)

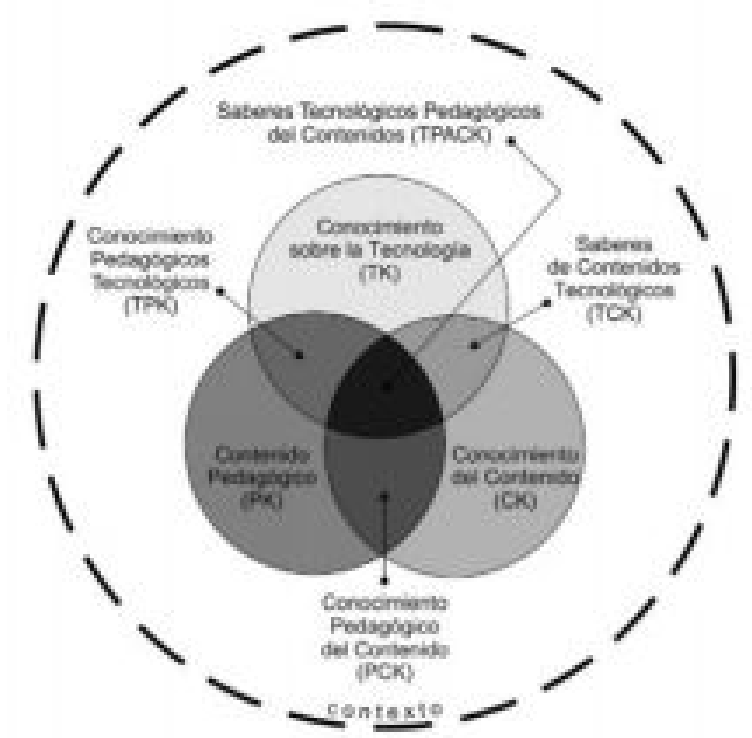

En suma, la integración del conocimiento propuesto en este modelo se da por la intersección de tres dimensiones primarias y otros tres productos de sus 
intersecciones que conducen a una construcción teórica denominada por los autores conocimiento tecno-pedagógico del contenido.

Se considera que ninguno de los anteriores encuadres conceptuales es suficiente por sí solo para caracterizar a las prácticas pedagógicas mediadas por TD. Al primero —en Huberman (1999) — le haría falta la referencia explícita a las tecnologías como componentes que atraviesan toda la práctica. Por otra parte, el modelo TPACK, en acuerdo con Cabero (2014, citado por Flores, Ortiz y Buontempo, 2018), omite algunos aspectos que se consideran fundamentales en este estudio, como los vinculados al proceso en el que se dan las prácticas, las concepciones sobre aprendizaje de los docentes y aspectos éticos e ideológicos, entre otros. Las mismas autoras desarrollan una serie de indicadores basados en el modelo citado y en competencias, que son tenidos en cuenta en la construcción de los instrumentos usados en esta investigación.

Dado que los cursos que se estudian interesan particularmente por su carácter técnico y la articulación entre la teoría y la práctica, la óptica de Pierre Pastré en su desarrollo de la didáctica profesional sirve de base para poder comprender cómo los docentes conceptualizan estos componentes. Pastré (2001; en Clot, 2007) hace referencia a dos modelos que coexisten en la práctica profesional con diferentes énfasis: el modelo operatorio — muchas veces presente en la enseñanza técnicacomo contrapuesto a modelos que se basan en conocimientos teóricos. La forma operatoria del conocimiento se corresponde según este autor a un «registro pragmático de conceptualización» (Pastré, 2006, p.5) que tiene por objeto orientar y guiar la acción, se presenta en contraposición a la forma predicativa, o discursiva, del conocimiento, que se expresa en enunciados y da lugar a saberes; pero alerta el autor, saber hacer no basta, hay que saber también cómo explicar lo que se hace para lograr desarrollar un modelo operatorio útil. Lograr complementar el hacer con un análisis reflexivo de la acción implica, en didáctica profesional, situaciones provenientes del trabajo transformadas en situaciones didácticas (Pastré, 2009).

Las posición docente frente al dilema entre la teoría y la práctica es otra dimensión que se ha considerado ya que, siguiendo a Vassiliades (2011), las relaciones con el saber y la enseñanza -y la cultura - no pueden estar predefinidas ni tampoco son fijas, por lo que se debe tener en cuenta la relación con las nuevas generaciones y entre la escolarización, el mundo del trabajo y la política; esta última categoría también se vincula con los problemas educacionales a los que se ven enfrentados los docentes y su posible solución a través de la enseñanza. En este caso de estudio particular, la relación entre la enseñanza de lo teórico y lo práctico está tensionada por la posición que los docentes tienen frente a ella, las particularidades de cada disciplina y el contexto semipresencial en el cual se desarrolla.

Los ECACP pueden caracterizarse, a partir de lo que se desprende de la revisión documental del plan de estudios vigente (CFE, 2018), por un criterio de asignación de 
créditos que se hace a una asignatura, en relación con la carga horaria del curso y la carga horaria que deberá dedicarle el estudiante por fuera del horario del curso: una hora reloj de curso teórico equivale a dos horas reloj de actividad del estudiante; una hora reloj de curso práctico, a una hora y media de actividad del estudiante. Es decir, al formato teórico se le aplica un coeficiente 2 por las horas de lectura y estudio que suponen, mientras que al formato práctico —Formación Técnica y Experimental—un coeficiente de 1.5, ya que la mayor parte de las tareas se realiza en simultáneo con el desarrollo del curso.

En esta investigación, el contexto en línea tiene un papel preponderante. Las TIC atraviesan el sistema educativo y las prácticas docentes; se establecen nuevas relaciones, formas de producción y transmisión a partir de su uso. Esto supondría reflexionar sobre el modelo pedagógico adoptado, reconociendo que «no hay un modelo universalmente válido» (Gatti, 2000, p.28). Estos conceptos son tenidos en cuenta al realizar el análisis de cada caso, su triangulación con las historias personales de los docentes (origen, formación, experiencia de enseñanza) y de la institución, desde sus orígenes como formadora de Maestros Técnicos y, particularmente, de la modalidad semipresencial.

Diversas estrategias del trabajo en taller, que se han relevado como fundamentales, se pueden englobar en la descripción que hace Finkel (2008), en cuanto implican una enseñanza activa, donde se realiza una propuesta interesante y desafiante que no se resuelve siguiendo una serie de instrucciones, sino que supone un desafío intelectual para los estudiantes. Se suman a esta ideas como la de Perkins (2010) sobre el aprendizaje pleno, o las de Wenger (2001) sobre el aprendizaje en comunidades de práctica, entre otras; todas de corte socioconstructivista (Vygotsky, 1979).

Las estrategias de enseñanza de los docentes se analizaron con base en elementos descriptos por diversos autores (Mayer, 1984; Shuell,1988; West, Farmer y Wolff, 1991, en Díaz Barriga, 1999) que definen y conceptualizan estrategias generales a las que se les ha agregado la localización en el aula virtual como modo de triangulación. También se han tenido en cuenta los diferentes tipos de actividades y trabajos prácticos adaptados a la enseñanza técnica a partir de la propuesta de Aureli Caamaño (1992) y las pautas para los trabajos de fin de carrera para Maestros Técnicos y Profesores Técnicos del CFE (2016). Las propuestas de evaluación que realizan los docentes -ya sea tareas de evaluación formativa y actividades y evaluaciones sumativas, como define el Plan 2017 citando a Sanmartí (2008)_ permiten mapear los niveles de comprensión que se intenta que sean aprendidos partiendo del supuesto del alineamiento constructivo entre objetivos, enseñanza y evaluación, que describe Biggs (2006).

Los modelos de enseñanza técnica y tecnológica, con los que se pueden corresponder las estrategias desplegadas por los docentes, se fundamentan en un 
Añón, Martínez y Perrone - Las prácticas pedagógicas mediadas por tecnologías digitales...

análisis internacional de la UNESCO (2005; en Leliwa, 2008) donde se identifican tres grandes tipos. El primero, procedimental, abarca aquellos que se enfocan en el desarrollo de habilidades y destrezas de tipo operatorio; el segundo, cientificista, concibe la tecnología supeditada a la ciencia; el tercero, integrador, la concibe como actividad teórico-práctica y reconoce el rol fundamental de las prácticas y técnicas, la creatividad y los procesos científicos, y la dimensión social de la ciencia y tecnología.

Se ha definido para el contexto de este estudio el concepto de materialidad, que estaría dado por ciertas propiedades del objeto que hacen que su enseñanza en la virtualidad conlleve mayores dificultades. Se establecen tres niveles de materialidad: alta, media y baja; en relación con ciertas características que se detallan en la siguiente tabla:

Tabla 1

Enumeración de características y propiedades que en su conjunto definen la materialidad de los contenidos de un curso (elaboración del equipo de investigadoras).

\begin{tabular}{|c|c|c|c|}
\hline \multicolumn{4}{|l|}{ MATERIALIDAD } \\
\hline & Baja & Medio & Alta \\
\hline \multicolumn{4}{|l|}{ Aspecto } \\
\hline Económico & $\begin{array}{l}\text { Materiales poco } \\
\text { costosos. }\end{array}$ & $\begin{array}{l}\text { Si resultan costosos } \\
\text { para el estudiante, se } \\
\text { pueden compartir los } \\
\text { gastos o bien la } \\
\text { institución puede } \\
\text { asumir los costos. }\end{array}$ & $\begin{array}{l}\text { Herramientas } \\
\text { instrumentos costosos } \\
\text { aun a nivel institucional. }\end{array}$ \\
\hline $\begin{array}{l}\text { Disponibilidad } \\
\text { para el usuario. }\end{array}$ & $\begin{array}{l}\text { Disponibles en el } \\
\text { mercado local, fáciles } \\
\text { de conseguir. }\end{array}$ & $\begin{array}{l}\text { La institución puede } \\
\text { cederlos en préstamo } \\
\text { para ser usado dentro } \\
\text { de sus instalaciones o } \\
\text { a través de convenios } \\
\text { con otras. }\end{array}$ & $\begin{array}{lrl}\text { De difícil } & \text { acceso } \\
\text { personal } 0 & \text { incluso } \\
\text { institucional. } & \end{array}$ \\
\hline $\begin{array}{l}\text { Seguridad en su } \\
\text { manipulación }\end{array}$ & Poco peligrosos & $\begin{array}{l}\text { Su peligrosidad es } \\
\text { relativa. }\end{array}$ & $\begin{array}{l}\text { Se debe usar en } \\
\text { determinadas } \\
\text { condiciones } \\
\text { seguridad para las } \\
\text { personas o el entorno. O } \\
\text { bien una mala } \\
\text { manipulación implica } \\
\text { altos costos. }\end{array}$ \\
\hline
\end{tabular}


Añón, Martínez y Perrone - Las prácticas pedagógicas mediadas por tecnologías digitales...

\begin{tabular}{|c|c|c|c|}
\hline $\begin{array}{l}\text { Existencias de } \\
\text { correlato digital }\end{array}$ & $\begin{array}{l}\text { Tienen un correlato } \\
\text { digital }\end{array}$ & $\begin{array}{l}\text { Correlato parcial o } \\
\text { de no tan buena } \\
\text { calidad pero que } \\
\text { aproxima su uso o es } \\
\text { suficiente para el nivel } \\
\text { de conocimientos del } \\
\text { curso. }\end{array}$ & $\begin{array}{l}\text { Sin correlato digital } \\
\text { existente o accesible. }\end{array}$ \\
\hline $\begin{array}{l}\text { Características } \\
\text { del correlato digital }\end{array}$ & 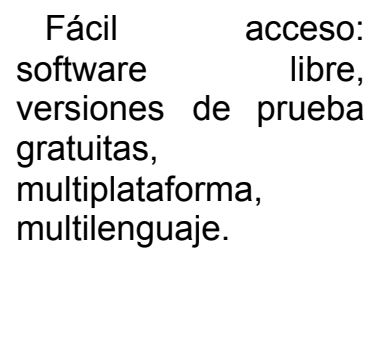 & $\begin{array}{l}\text { A través de alguna } \\
\text { estrategia se puede } \\
\text { acceder: versiones } \\
\text { limitadas (trial, demo, } \\
\text { educativas), uso de } \\
\text { traductores, } \\
\text { conversores } \\
\text { formatos, etc. de }\end{array}$ & $\begin{array}{l}\text { En caso de existir es } \\
\text { costoso o no se puede } \\
\text { acceder por otro tipo de } \\
\text { limitaciones. }\end{array}$ \\
\hline $\begin{array}{l}\text { Conocimientos } \\
\text { técnicos requeridos }\end{array}$ & $\begin{array}{lr}\quad \text { De } & \text { fácil } \\
\text { manipulación: } & \text { no } \\
\text { requiere } & \text { de } \\
\text { conocimientos } & \\
\text { informáticos } & \\
\text { avanzados. } & \end{array}$ & $\begin{array}{l}\text { Con una guía } \\
\text { adecuada se puede } \\
\text { acceder por lo menos } \\
\text { a parte de sus } \\
\text { prestaciones. }\end{array}$ & $\begin{array}{l}\text { Se necesita un } \\
\text { entrenamiento } \\
\text { especializado para su } \\
\text { uso. }\end{array}$ \\
\hline Soporte técnico & $\begin{array}{l}\text { Se dispone de } \\
\text { soporte en variados } \\
\text { formatos para su uso: } \\
\text { foros de consulta, } \\
\text { comunidades de } \\
\text { apoyo, videotutoriales, } \\
\text { manuales, etc. }\end{array}$ & $\begin{array}{l}\text { Se dispone de algún } \\
\text { tipo de soporte por lo } \\
\text { menos en forma } \\
\text { parcial. }\end{array}$ & $\begin{array}{l}\text { No se dispone o es } \\
\text { inaccesible por costos, } \\
\text { idioma, conocimientos } \\
\text { requeridos, etc. }\end{array}$ \\
\hline
\end{tabular}

En esta investigación, el concepto de virtualización, creación a través de software de una versión virtual de algún recurso tecnológico (Wikipedia, s.f.), se ha ampliado incluyendo el análisis de la «versión virtual» de las prácticas de los docentes, la forma en que mejoran, transforman, o no, sus prácticas pedagógicas para que, a través de la mediación con TD y en un contexto virtual, logren sus objetivos de enseñanza. Es un concepto íntimamente relacionado con el modelo TPACK del conocimiento del docente y con el nivel SAMR de transformación del ambiente de aprendizaje a través del uso de las TD que este implemente. Este último concepto fue desarrollado por Puentedura (2006) y es el acrónimo de Sustituir, Aumentar, Modificar y Redefinir, que implica acciones sucesivas para transformar los ambientes de aprendizaje con el uso de las TIC, es decir, el empleo de la tecnología para sustituir o mejorar funcionalmente las prácticas tradicionales o, yendo más allá, para que realmente operen modificaciones o propuestas novedosas que redefinan lo establecido. 


\section{Diseño metodológico}

Se elaboró un estudio descriptivo de las prácticas pedagógicas mediadas por las TD, que los docentes de los ECACP realizaron en el contexto de sus cursos semipresenciales. Se indagó en las características de las estrategias de enseñanza desarrolladas, identificándose algunas particularidades del contexto, mediado o no por TD, en que estas se dan.

Se optó por una metodología cualitativa con fines descriptivos: se «busca caracterizar y especificar propiedades» (Batthyàny y Cabrera, 2011 p.33) sin pretender llegar a una modalidad explicativa que indague en las causas de estas prácticas. De todas maneras, no se descartó que pudieran emerger algunas hipótesis en ese sentido, pero serían objeto de otro estudio.

\section{Unidad de análisis, tipo de muestra, instrumentos y validación}

Se estudiaron las prácticas pedagógicas de tres docentes de asignaturas denominadas de alto contenido práctico correspondientes a las carreras en modalidad semipresencial para la formación de Maestro Técnico (MT) del Área Agraria y del Área Eléctrica y de la Tecnicatura de Asistente Docente de Laboratorio en Tecnologías Digitales también de esta área, todas carreras de formación docente con perfiles distintos.

En el desarrollo de la investigación se realizó:

- Un muestreo de tipo intencional, no aleatorio, atendiendo al carácter eminentemente práctico de la asignatura y a la disponibilidad del docente para colaborar en la investigación, que se enmarca en un estudio de casos.

- Entrevistas semiestructuradas, cuyos datos obtenidos se cruzaron con los de las observaciones de las aulas virtuales. Las dimensiones observadas en las aulas guardan relación con los marcos teóricos desarrollados oportunamente y sirvieron de base para la operacionalización de conceptos.

- La triangulación del análisis documental vinculado con los espacios curriculares como talleres o asignaturas prácticas, o la modalidad semipresencial.

Durante la etapa de análisis se partió de categorías preestablecidas a las que se sumaron las que fueron emergiendo durante la codificación de las entrevistas -fruto de una metodología basada en la teoría fundamentada de Strauss y Glaser (1967; en Sandoval, 1997)—. Así se revisó y se profundizó en el análisis de las observaciones de las aulas virtuales con nuevas perspectivas.

El equipo de investigación contó con integrantes de diferentes ámbitos de especialización, lo que hizo posible contrastar distintas visiones, perspectivas, estrategias en el trabajo de campo y en el registro, análisis y validación de la información. En este sentido, Taylor y Bodgan (1987), citando a Douglas (1976), lo 
Añón, Martínez y Perrone - Las prácticas pedagógicas mediadas por tecnologías digitales...

destacan como una alternativa al enfoque tradicional de trabajo en solitario en el campo:

La investigación en equipo también permite un alto grado de flexibilidad en las estrategias y tácticas investigativas. [...] estableciendo reglas básicas claras en lo que concierne a las responsabilidades de cada persona, asegurando que esa gente podrá trabajar junta, antes de iniciar el trabajo en equipo (p.93).

En esta investigación se trabajó en duplas durante la recolección de datos, para luego contrastar los registros de la información obtenida mediante los distintos instrumentos existentes. Esto permitió enriquecer el análisis, al tener en cuenta las múltiples interpretaciones sobre un mismo fenómeno.

\section{Resultados}

Se presenta una breve síntesis de la caracterización de las prácticas pedagógicas de los espacios curriculares analizados a partir de la triangulación de los datos recabados en las entrevistas, con la observación de aulas virtuales y apoyados en la revisión documental. Para preservar la identidad de los docentes, se han nombrado sus espacios curriculares como ECACP 1, ECACP 2 y ECACP 3.

El ECACP 1 corresponde a un curso del Área de Tecnologías Eléctricas y Digitales vinculado con la producción audiovisual. Se ubicó, de acuerdo con los criterios establecidos en la tabla 1, en un nivel de materialidad media. El docente a cargo manifestó que el componente práctico de su curso es muy alto y explicó que decidió relegar lo teórico en su aula virtual, aunque lo suele abordar en instancias presenciales, pues consideró que sus estudiantes podrían articular ambos aspectos en la síntesis que realizaran al entregar las tareas y su fundamentación. Describió estas tareas - resolución de problemas en contextos reales - como desafíos similares a los que un profesional del área podría afrontar en el campo laboral, lo que parece vincularse también con el hecho que el docente está formado como profesional universitario. Según lo que declaró, existe una analogía entre la relación docente-estudiante y la de cliente-desarrollador. Además, describió estrategias de enseñanza que apuntan hacia el fortalecimiento de la autonomía del estudiante, con retroalimentación en instancias presenciales para favorecerla.

Al analizar su aula virtual desde el modelo TPACK, y más específicamente en el componente que supone una articulación entre lo pedagógico y lo tecnológico, no se identificó el mismo tipo de estrategias orientadas al desarrollo de la autonomía a través de la retroalimentación, por ejemplo, con el uso de foros de discusión, pautas de elaboración o ejemplificación de los trabajos. En su aula virtual se observaron los materiales organizados en carpetas, pero no se identificaron soportes para su navegación, como pueden ser guías didácticas, hojas de ruta, calendarios u organizadores gráficos; de la entrevista surgió que el docente asigna gran 
importancia a los encuentros presenciales para indicar esas pautas de cursado. Se pudo constatar que los recursos usados con fines didácticos son textos enriquecidos con imágenes y enlaces a videos de terceros seleccionados en YouTube. En las consignas escritas se menciona el uso de software específico de edición para generar los productos solicitados y en el aula se facilitan enlaces a videotutoriales.

Del análisis de las observaciones del aula y de acuerdo con las descripciones hechas por el docente se considera que, en este caso, se usan las TD como forma de sustituir y aumentar las prácticas tradicionales según el modelo SAMR (Puentedura, 2006), por lo que la virtualización del curso es limitada.

El ECACP 2 corresponde a un taller de laboratorio del Área de Tecnologías Eléctricas y Digitales, relacionado con la Electrónica. El docente de este curso, que es Maestro Técnico, demostró, a través de sus explicaciones y argumentaciones, formación específica en lo pedagógico, que pone en juego en sus propuestas. Se vale de la tecnología disponible, especialmente en las actividades de enseñanza.

Este espacio curricular tiene un marcado acento práctico, siendo de baja materialidad y de una virtualización accesible (tabla 1). Los costos de los materiales no son elevados, se adquieren fácilmente en el mercado y son de poca peligrosidad. Además, encontramos instrumentos similares en la digitalidad (simuladores) en los que se pueden realizar las prácticas propuestas. En este caso, la virtualización de los materiales y del curso es altamente factible. Un docente, aun con un conocimiento básico del campo de lo tecnopedagógico podría disponer fácilmente de los elementos necesarios para sustituir sus prácticas tradicionales, modificarlas 0 incluso redefinirlas con el uso de las tecnologías.

El docente del ECACP 2 aprovechó estas características y describió variadas estrategias de enseñanza que ponen en evidencia la virtualización, lo que pudo comprobarse al observar su aula virtual (las consignas, las tareas entregadas y la retroalimentación realizadas $y$, los recursos ofrecidos). Se deduce, además, de la entrevista y algunas intervenciones de los estudiantes en los foros, que es probable que se utilicen aún más recursos para virtualizar que no han quedado registrados en la plataforma ya que se realizaron a través de videoconferencias y de WhatsApp.

Los recursos utilizados en sus prácticas pedagógicas en el aula virtual incluyen videos demostrativos y enlaces a fuentes de universidades extranjeras. Los recursos didácticos en las propuestas de evaluación formativa en general son textos elaborados por el docente acompañados de imágenes (por ejemplo, usando un determinado instrumento de medición o un gráfico obtenido en un simulador), y cuestionarios con preguntas cerradas. También propuso tareas en las que los estudiantes debían realizar entregas que debían subir a la plataforma, retroalimentándose tanto de la calificación obtenida como de los comentarios del 
docente. De acuerdo con lo constatado en la observación del aula virtual, las entregas de los estudiantes a estas consignas consisten en documentos con textos de solución a problemas, imágenes demostrativas del uso de ciertos instrumentos y capturas de pantalla del uso de simuladores. También se pudo constatar la elaboración de tablas de datos y gráficos. En cuanto a los recursos de comunicación se observa un amplio despliegue en su aula: anuncios (para comunicaciones y novedades), foros, comentarios a tareas y mensajes. Es posible observar que, en general, los recursos y las TD son usados para aumentar, modificar e incluso sustituir las prácticas tradicionales en el sentido del modelo SAMR ya mencionado.

En la entrevista, el docente del ECACP 2 menciona que valora la interacción y el aprendizaje en un ambiente lo suficientemente flexible como para que los estudiantes puedan desarrollar aprendizajes creativos y tendientes a la solución de problemas, lo que se constata en el uso de variados medios de comunicación. Entre las estrategias de enseñanza incluye varias que apuntan al desarrollo de la autonomía del estudiante, pues pauta las consignas con niveles crecientes de complejidad y exigencias cognitivas. No se ofrece lo teórico al estudiante para que este realice la articulación en la praxis, sino que alienta, como se constata en algún foro de discusión, el ejercicio de la confrontación de ideas y la argumentación sobre lo teórico. Cuando el docente, más allá de que lo logre implementar o no, lo usa como estrategia, podría estar revelando, que parte de una concepción que se aproxima más a la de Pastré, en cuanto el modelo operatorio, se sustenta sobre un modelo cognitivo empírico donde este marco teórico de la conceptualización en la acción, permite, al menos, comprender cómo se hace la elaboración de la acción (Pastré, 2006).

El ECACP 3 corresponde a un curso del Área Agraria, que trata sobre la maquinaria agrícola. Su docente, profesional universitario, planteó en la entrevista su convicción de que los conocimientos teóricos son una condición necesaria y previa para la adquisición de las destrezas prácticas de la práctica profesional. En línea con lo anterior, adoptó en su aula virtual un enfoque teórico, que lo hace más fácilmente virtualizable. De acuerdo con lo planteado en el marco teórico y lo presentado en la tabla 1, y de lo que surge del análisis de la documentación sobre el plan y programa de la asignatura, este curso es de alta materialidad. Los materiales necesarios para este son de un costo elevado, por lo que su acceso es difícil. Además de ello, la manipulación del material implica condiciones de seguridad a seguir porque puede tener riesgos, no solo personales, sino de costos, asociados a una mala manipulación. Si bien el docente manifestó conocer herramientas digitales de valor equiparable (simuladores), no son de fácil acceso y son costosos como para compartir en su curso.

Sobre los recursos observados en el aula virtual, la mayoría sirven como expositores de contenidos teóricos: textos escritos, síntesis en forma de presentaciones, 
manuales completos sobre el uso de las herramientas y algunos videos. También se observa el uso de foros, pero, tal como el propio docente menciona en la entrevista, no hay evidencia de interacción en los mismos.

El uso de las TD observado es, principalmente, de sustitución de las prácticas tradicionales en una plataforma educativa, de acuerdo con lo planteado en el modelo SAMR. Si bien el docente menciona cierta adaptación de los contenidos (inclusión de más textos explicativos en una presentación, uso de imágenes y videos, por ejemplo), esta no constituye una transformación significativa de los contenidos para ser presentados en el ambiente virtual.

\section{Síntesis de los casos estudiados}

En los tres casos analizados se presenta un espectro de concepciones sobre la relación entre la teoría y la práctica que expone un modelo más integrador, donde ambos componentes se articulan para lograr un conocimiento integrado (ECACP 2); otro en el que, si bien se consideran valiosos y necesarios ambos componentes, su articulación no parece tan evidente (ECACP 1); y, por último, una propuesta donde la concepción de lo teórico y lo práctico hace incluso cuestionar la consideración que las investigadoras hicieron del curso (ECACP 3) como un espacio curricular con alto contenido práctico.

Los profesores utilizan algunos métodos de enseñanza activos (estudio de casos, trabajo por proyectos, resolución de problemas) donde despliegan una serie de estrategias y técnicas de enseñanza, algunas de las cuales están alineadas con el Plan 2017. Más allá de la estrategia empleada, los docentes entrevistados coinciden en la necesidad de estimular procesos cognitivos que trasciendan la aplicación de la técnica, superando así el modelo procedimental de su enseñanza (Leliwa, 2008). Destacan la importancia de los procesos de reflexión y análisis consciente, de y sobre las acciones operativas. Al menos los docentes del ECACP 1 y 2 , desde la intencionalidad, se aproximan a un modelo integrador de la enseñanza técnica siendo el caso del ECACP 3 el que refleja un modelo más próximo a los que conciben la tecnología como supeditada y al servicio de ciencia. Este aspecto está íntimamente vinculado a las concepciones sobre teoría y práctica que tienen los docentes.

De acuerdo con la revisión documental realizada en el Plan 2017, se menciona el valor del trabajo individual y también el colectivo, especialmente vinculado a la evaluación. En el ECACP 1 prevalece una visión tradicional de la evaluación, que enfatiza lo individual sobre lo colectivo. El docente argumenta que no propone trabajos grupales, ya que le sería difícil identificar el aporte de cada uno de los integrantes del equipo sin contar con una instancia de defensa. Hay algunas propuestas de un proyecto final grupal correspondientes al ECACP 3 , y otras de tareas formativas colectivas en los ECACP 1 y 2 , pero no hay evidencia en las aulas de cuál 
Añón, Martínez y Perrone - Las prácticas pedagógicas mediadas por tecnologías digitales...

fue la estrategia que el docente desarrolló, en cada caso, para identificar el aporte de cada integrante del equipo.

El análisis de las consignas y las actividades propuestas en cada una de las aulas virtuales estudiadas, así como el análisis de la información que surge en las entrevistas permiten identificar tanto coincidencias como perspectivas diferentes en los planteos docentes. En cuanto a la formulación de las consignas podríamos pensar en dos enfoques diferentes que se proponen para el desarrollo de tareas de tipo experimentales o de experiencias prácticas:

- Unas serían propuestas a modo de ejercicios prácticos procedimentales que desglosan las actividades en una visión atomista de los procedimientos, lo que permite gradarlos antes de abordar tareas de tipo investigativo que implican un abordaje integrador.

- Otras son consignas con enunciados de tipo global, donde el desafío se plantea desde el inicio en toda su complejidad en línea con los planteos de aprendizaje pleno ${ }^{4}$ —desarrollado en el Proyecto Cero de Harvard- (Gardner, 2013).

Dos de los docentes (ECACP 1 y ECACP 2) fundan sus consignas en la resolución de una situación problemática. Como particularidad en el caso del ECACP 2, el docente desglosa la consigna pasando por una serie de actividades gradadas que implican el reconocimiento de las herramientas y materiales utilizados, su utilización, la sistematización de los resultados obtenidos y como cierre, una aplicación a modo de resolución de problema. Este docente incluye algún trabajo donde combina ambos tipos de consignas. En el ECACP 1, se proponen consignas con un planteo del tipo de resolución de problemas global en las que no se hace un desglose de cada una de las actividades requeridas en forma de secuencia de creciente complejidad, sino que se plantea un problema contextualizado, un caso a resolver. Se puede afirmar que el caso del ECACP 3 es un tanto diferente, ya que, si bien el contenido del curso se orienta al estudio de un objeto tecnológico y fue considerado de alta materialidad, las consignas de las tareas observadas en su aula incluyen un reconocimiento indirecto de su estructura y un abordaje teórico de su función. No está explicitada una interacción real con el objeto, se hace a través de alguna imagen prediseñada de alguna de sus partes o, eventualmente, del objeto real, si es que los estudiantes tienen acceso a él por sus propios medios. Las consignas de actividades en este curso implican preguntas que se resuelven principalmente leyendo los contenidos teóricos o eventualmente realizando algún cálculo; en los hechos no es necesaria la mediación con el objeto de estudio más allá de alguna representación parcial de este mediante una ilustración. En este caso, el docente, durante la entrevista, reconoció

\footnotetext{
${ }^{4}$ El modelo teórico del aprendizaje pleno implica desarrollar nuevos conocimientos, habilidades, destrezas, que pueden utilizarse en situaciones diferentes de los contextos donde se aprendieron. Implica propuestas holísticas del problema, desplegando toda su complejidad desde el inicio, tal como se presentan en la vida real.
} 
Añón, Martínez y Perrone - Las prácticas pedagógicas mediadas por tecnologías digitales...

este enfoque teórico como una debilidad y lo justificó con las dificultades para su virtualización.

En relación con el proceso y las concepciones de la evaluación, podemos ver que el docente del ECACP 2 exige que los estudiantes cumplan con la entrega a partir de una consigna y le da importancia al proceso, al recorrido que hizo el estudiante para llegar a su resolución. En este caso hay intercambio y retroalimentación durante el proceso de elaboración de las tareas que se confirma en el curso virtual. Si bien en las consignas de los docentes de los ECACP 1 y 3 figuran especificaciones relativas a la producción de la tarea, no se solicita a los estudiantes que den cuenta del proceso de elaboración, por ejemplo a través de capturas de pantalla que progresivamente muestran el uso del programa, o de la grabación de videos que pongan en evidencia el progreso, se corrigen las entregas finales de los alumnos, sin que estas evidencien el proceso por el cual se llegó a lo entregado ni una retroalimentación intermedia.

Los profesores entrevistados provienen de diferentes campos profesionales, tienen distinta experiencia en la enseñanza o grados de formación docente, además de ser diferentes sus edades y contextos personales. A partir del análisis de las entrevistas, las aulas virtuales y la documentación, se ha visto que en uno de los casos abordados el docente que debe enfrentar un curso de más alta materialidad y, por ende, de mayor dificultad para la virtualización, es, además, el que tiene una menor formación específica en educación y un menor conocimiento tecnopedagógico del contenido. Queda claro que la materialidad, tal como fue definida, es una propiedad inherente a cada curso y que en escasa medida se puede modificar por la acción docente o institucional, más bien depende de los avances y desarrollos tecnológicos.

Si bien todos los docentes entrevistados manifiestan haber tenido por lo menos alguna experiencia previa o cursos vinculados a la enseñanza en la virtualidad, estos se basaron principalmente en formaciones para el uso de la plataforma y esquemas generales de diseño de un curso. Los docentes se muestran interesados en continuar aprendiendo a enseñar en un aula virtual, aunque reconocen no aprovechar toda la potencialidad de las TD como mediadoras y que no siempre identifican los modos de hacerlo.

\section{Conclusiones}

Es frecuente en las prácticas pedagógicas identificar un traslado de las lógicas presenciales a las virtuales. En línea con hallazgos de Ospina y colaboradores (2015), serían tres los factores determinantes en la dificultad para generar estrategias didácticas propias de la virtualidad por parte de los docentes: la escasa apropiación tecnológica de los docentes y, por lo tanto, la dificultad de relacionarlo con el aspecto educativo; la falta de requisitos desde las instituciones para con los docentes en los aspectos relacionados con la experiencia y capacitación en educación virtual; y las restricciones que las plataformas virtuales pueden presentar para una enseñanza 
Añón, Martínez y Perrone - Las prácticas pedagógicas mediadas por tecnologías digitales...

libre y acorde al contexto. Los tres aspectos se tuvieron en cuenta durante el análisis y se pudo constatar que, en la medida en que los docentes profundizan en la reflexión sobre sus prácticas y se ven desafiados a trabajar en diferentes contextos a los habituales (como lo es la modalidad semipresencial), se enfrentan a variados escenarios educativos y comienzan a modificar sus prácticas (reelaboran materiales, seleccionan recursos digitales ilustrativos de lo que antes explicaban en el laboratorio o el taller, solicitan a los estudiantes nuevos formatos de documentación de sus tareas como las imágenes o los videos).

La formación de Maestros Técnicos es muy particular, pues se da en ella un cruce muy marcado entre la actividad propiamente profesional y la formación docente. Dada la complejidad del perfil que se requiere, el formador de formadores es demandado, porque debe poseer gran solvencia técnica en el desempeño profesional práctico o en el campo de trabajo, además de abundantes estrategias para la enseñanza en su campo técnico y también didáctico, ya que orienta a futuros docentes. Se suma a estas demandas el contexto virtual en que se desarrolla la mayor parte de la enseñanza de esta modalidad.

Al analizar la posición de los docentes frente a la teoría y la práctica, se pone en evidencia cómo esta categoría está fuertemente influida por la formación y experiencia del docente. Estas atraviesan a las demás categorías y, en buena medida, las determinan y parecen explicar las decisiones que los profesores toman sobre las prácticas pedagógicas. Se suma a esta particularidad el hallazgo emergente de esta investigación, que ha sido la necesidad de definir la materialidad como una característica de los espacios curriculares de alto contenido práctico, fuertemente vinculada a sus posibilidades de virtualización. De ser considerada por la institución, puede facilitar la organización y gestión de los cursos teniendo en cuenta esta propiedad.

De esta investigación se desprenden varias áreas donde se encontraron márgenes para mejorar las prácticas pedagógicas mediadas por TD en espacios curriculares de alto contenido práctico: en el diseño de los cursos; en lo relativo a la formación tecnopedagógica de los docentes; en aspectos vinculados con lo institucional (recursos humanos, infraestructura, creación y difusión de conocimiento); en lo referente a la formación de los estudiantes; y en cuanto al plan de estudios y a las posibilidades y limitaciones de las plataformas virtuales utilizadas.

En tanto proyección de esta investigación, se plantea como una interesante posibilidad la de explorar en los estudiantes aspectos vinculados con el desarrollo de competencias en el uso de las TD y, más específicamente, en las requeridas para un cursado semipresencial, incluso las habilidades de aprendizaje que esta modalidad requiere. A su vez, cabe preguntarse cuáles son las posibilidades de que se integre otras plataformas y dispositivos y cómo esto podría influir en el seguimiento de los cursos. Otra proyección que se considera posible es que se comiencen a identificar 
Añón, Martínez y Perrone - Las prácticas pedagógicas mediadas por tecnologías digitales...

aspectos transversales propios de una didáctica de la enseñanza virtual que implicaría, como se propone en el modelo TPACK, un entrelazamiento entre el componente tecnológico y pedagógico del conocimiento, tanto de los contenidos como desde las competencias que deben tener los docentes.

\section{Bibliografía}

Alliaud, A. (2005). Historias encontradas de la docencia en la Argentina [Entrevista de Daniel Brailovsky]. Organización Infancia en Red.

Alliaud, A. (2017). Los artesanos de la enseñanza. Acerca de la formación de maestros con oficio. Buenos Aires, Argentina: Paidós.

ANEP-CFE (2016). Acta 30 Res. 36. Normativa de trabajos de fin de carrera para Maestro Técnico y Profesor Técnico del 26 de octubre de 2016.

ANEP- CFE (2016). Documento de Fundamentos y Orientaciones de la propuesta 2017. Montevideo, 11 de noviembre de 2016

Batthyàny, K., Cabrera, M. (2011). Metodología de la investigación en Ciencias Sociales. Apuntes para un curso inicial. Recuperado de http://cienciassociales.edu.uy/departamentodesociologia/wp-content/uploads/sites/ 3/20 13/archivos/FCS_Batthianny_2011-07-27-imprimir.pdf

Biggs, J.B. (2006). Calidad del aprendizaje universitario. Madrid, España: Narcea S.A Cabero, J. (2014). La formación del profesorado en TIC: Modelo TPACK (Conocimiento Tecnológico, Pedagógico y de Contenido). Sevilla, España: Secretariado de Recursos Audiovisuales y Nuevas Tecnologías de la Universidad de Sevilla.

Caamaño, A. (1992). Los trabajos prácticos en ciencias experimentales. Una reflexión sobre sus objetivos y una propuesta para su diversificación. Aula de Innovación Educativa, 9.

CFE (2017). Estudio sobre la modalidad de formación semipresencial del Consejo de Formación en Educación. Conde A.L., González Burgstaller M., Villagrán A. Expediente $\mathrm{N}^{\circ}$ : 2018-25-5-000442

CFE (2018). Plan 2017 de Maestro Técnico, Profesor Técnico y Asistente Docente de Laboratorio de Tecnologías. Recuperado de http://www.cfe.edu.uy/images/stories/pdfs/planes_programas/a44_res36.pdf

Clot, Y. (2007). De l'analyse des pratiques au développement des métiers. Éducation et didactique 1(1). Recuperado de http://educationdidactique.revues.org/106/Ce

Díaz Barriga, F., Hernández, G. (1999). Estrategias de enseñanza para la promoción de aprendizajes. En: Estrategias docentes para un aprendizaje significativo. Ciudad de México, México: Mcgraw-Hill Interamericana. Recuperado de: http://dip.una.edu.ve/mpe/025disenoinstruccional/lecturas/Unidad_III/EstratDocPar aU nAprendSignif.pdf

Douglas, J. (1976). Investigative social research: individual and team field research. Sage Publications.

Finkel, D. (2008). Dar clase con la boca cerrada. Barcelona, España: Publicacions de la Universitat de València 
Añón, Martínez y Perrone - Las prácticas pedagógicas mediadas por tecnologías digitales...

Flores, F.A., Ortiz, M.C. y Buontempo, M.P. (2018). TPACK: un modelo para analizar prácticas docentes universitarias. El caso de una docente experta. REDU. Revista de Docencia Universitaria, 16(1), 119-136

Gardner H. (2013). Harvard Project Zero: a personal history. Recuperado de http://www.pz.harvard.edu/sites/default/files/pz-history-9-10-13.pdf

Gatti, E., (2000): Modelos Pedagógicos en la Educación Superior. Temas y Propuestas.

Koehler, M. J. y Mishra, P. (2005). What happens when teachers design educational technology? The development of technological pedagogical content knowledge. Journal of Educational Computing Research, 32(2), pp.131-152.

Koehler, M. J., Mishra, P. y Cain, W. (2013). What Is Technological Pedagogical Content Knowledge (TPACK)? Journal of education, 193(3), pp.13-20.

Leliwa, S. (2008). Enseñar educación tecnológica en los escenarios actuales. México: Editorial Comunicarte.

Montero, M. (2016). La biografía escolar como instrumento para la reflexión de los conocimientos previos y construidos durante la formación docente entorno al «cómo enseñar». Ensayos Pedagógicos 11(2), pp.83-97.

Ospina, D., Pelaez, L.. (2015). Didácticas en la educación virtual: de la prolongación de la presencialidad, al reto de innovar. Recuperado de https://www.researchgate.net/profile/Daniel_Ospina6/publication/304626451_Didac tias_en_la_educacion_virtual_de_la_prolongacion_de_la_presencialidad_al_reto_ de_innovar/links/57753f5208ae4645d60ba8df/Didacticas-en-la-educacion-virtual-d e-la-pr olongacion-de-la-presencialidad-al-reto-de-innovar.pdf

Pastré P. (2001). Analyse du travail et didactique professionnelle. Rencontre du CAFOC. Nantes. Recuperado de www.cafoc.ac-nantes.fr/ficpdf/.../analysetravail.pdf. Cosultado el 26/07/2018.

Pastré P. (2006), Apprendre à faire, in: Bourgeois Étienne (dir.), Chapelle Gaëtane (dir.). - Apprendre et faire apprendre. - Paris: Puf, 2006.- pp. 109-121. (Traducción disponible en

http://www.ceip.edu.uy/documentos/2018/ifs/dapg/materiales/Pastre,_P._-_Aprender_ a_hacer.doc

Pastré, P. (2009). (Ed.). Le but de l'analyse du travail en didactique professionnelle: développementet/ouprofessionnalisation? pp. 159-189. Paris, Francia. (Trad. profas. S Núñez y A. Zavala).

Perkins, D. (2010). El aprendizaje pleno: principios de la enseñanza para transformar la educación. Buenos Aires, Argentina: Paidós.

Pozo J. I. (2014) Psicología del aprendizaje humano. Adquisición de conocimiento y cambio personal. Madrid, España: Morata.

Puentedura, R. (2006). Transformation, Technology, and Education. Recuperado de http://hippasus.com/resources/tte/

Sandoval, C. (1997). Programa de especialización en teoría, métodos y técnicas de investigación social. Investigación cualitativa. Módulo 4. Medellín, Colombia: Universidad de Antioquía. 
Sanmartí, N. (2008). Evaluar para aprender, 10 ideas clave. Barcelona, España: Ed. Graó.

Vassiliades, A. (2011). Posiciones docentes frente a la desigualdad educativa. Disputas y tramas de sentido en torno de las regulaciones del trabajo de enseñar. Revista del Instituto de Investigaciones en Ciencias de la Educación Recuperado de http://revistascientificas.filo.uba.ar/index.php/iice/article/view/148

Vigotsky, L. (1979). El desarrollo de los procesos psicológicos superiores. Barcelona, España: Crítica.

Wikipedia. (s. f.). Virtualización. Recuperado el 14 de octubre de 2020, de https://es.wikipedia.org/wiki/Virtualizaci\%C3\%B3n

Wenger, E. (2001). Comunidades de práctica: Aprendizaje, significado e identidad. Barcelona, España: Paidós. 